\title{
Hydrocarbon species in SI and HCCI engine using winter grade commercial gasoline
}

The study provides a qualitative and quantitative analysis of the C5-C11 hydrocarbon species generated in Spark Ignition Homogeneous Charge Compression Ignition (SI/HCCI) gasoline direct injection (GDI) engine at range of operating conditions. The presented results and data were obtained from the combustion of winter grade commercial gasoline containing $2 \%$ w/w ethanol $\left(\mathrm{C}_{2} \mathrm{H}_{5} \mathrm{OH}\right)$ for the engine operated in steady-state, fully warmed-up condition. The hydrocarbon analysis in exhaust gases was executed on a Gas Chromatography-Mass Spectrometer (GC-MS) apparatus directly connected to the engine exhaust via heated line.

The highest concentration of the total hydrocarbon emissions was obtained under low load HCCI engine operation at stoichiometric fuel-air ratio. The major hydrocarbon compounds detected in the collected samples were benzene, toluene, p-xylene, and naphthalene. Benzene originates from the incomplete combustion of toluene and other alkylbenzenes which are of considerable environmental interest.

During the SI engine operation, increase of the engine speed and load resulted in the increase of benzene and the total olefinic species with simultaneous decrease in isopentane and isooctane. The same trends are seen with the engine operating under HCCI mode, but since the combustion temperature is always lower than SI mode under the same engine conditions, the oxidation of fuel paraffin in the former case was less. As a result, the total olefins and benzene levels in HCCI mode were lower than the corresponding amount observed in SI mode. Aromatic compounds (e.g., toluene), except for benzene, were produced at lower levels in the exhaust when the engine speed and load for both modes were increased.

Key words: homogeneous charge compression ignition (HCCI), Gas chromatography-mass spectrometer (GC-MS), hydrocarbon speciation, regulated and unregulated emissions

\section{Introduction}

Individual hydrocarbon species from the combustion of fuel such as oxygenated and polycyclic aromatic hydrocarbons (formaldehyde, acetaldehyde, benzene, 1,3 butadiene and polycyclic organic material) have been reported as health risk components.

Benzene enrichment from aromatic fuels is of considerable environmental interest. A risk assessment by Johnson et al. [1] indicates that an exposure of 1-5 ppm in ambient air for 40 years is associated with an increased risk of acute myeloid leukaemia. Based on the epidemiological evidence, benzene is considered as a human carcinogen (group 1) by the International Agency for Research on Cancer (IARC). Benzene and 1,3-butadiene are classified by the US Environmental Protection Agency (EPA) as group B2 probable human carcinogen of medium carcinogenic hazards [2]. Although for Toluene the pronounced toxic effects of high and long-term exposure are well-known [3, 4], the health effects of short-term exposure remain uncertain. Toluene, ethylbenzene and xylenes negatively affects the central nervous system, disturbed coordination, causes drowsiness, headache [5, 6] and mental disorders ATSDR [7].

Although, in modern vehicles corrective solutions in eliminating pollutants are available, such as the use of catalytic converters, a preventive technology is always preferable, which requires a good understanding of the in-cylinder air-fuel mixing and combustion processes. Detailed hydrocarbon emissions analysis, including speciation and quantification, is a powerful tool that can be used to understand the significance of the fuel composition and additives, engine operating conditions and emission control hardware, on the hydrocarbon component formation and help in the optimization of the combustion process.
Gasoline-fuelled engines will continue to be one of the main choices for passenger cars, therefore improving fuel efficiency and reducing the emission of toxic non-regulated yet compounds are of great importance [8]. Gasoline Homogeneous Charge Compression Ignition (HCCI) Engines have the potential to reduce significantly nitrogen oxides $\left(\mathrm{NO}_{\mathrm{x}}\right)$ emission and improve fuel consumption, under certain speed-load operating conditions in comparison to Spark Ignition (SI) operating mode [9].

Studies on the analysis of the hydrocarbon species in the exhaust gas of the SI engines started as early as the middle of 1950s by Walker and O'Hara [10]. Much work has been completed using the (GC-MS) technique by researchers in automotive industry

One of the early studies on the hydrocarbons species in the HCCI engine exhaust from the combustion of pure hydrocarbon components was carried out by [11]. Three different saturated hydrocarbons (n-pentane, n-hexane, and n-heptane); were studied; and their ignitability was also investigated. In the case of n-hexane fuel, at low-temperature combustion, olefins such as 1-hexene and 2-hexene and aldehydes were the products of oxidation, and olefins such as 1-butene, propylene, and ethylene were the product of decomposition (Scheme I). In the case of n-heptane fuel, the percentage olefins formed is less than the corresponding percentage formed from n-hexane combustion; 2-ethyl-3methyl-oxetane and other cyclic ethers were also detected. The results obtained from the n-pentane oxidation process were similar to the results obtained from n-hexane, but the accumulation of olefins and aldehydes during the lowtemperature oxidation period was greater than that seen in n-hexane case 


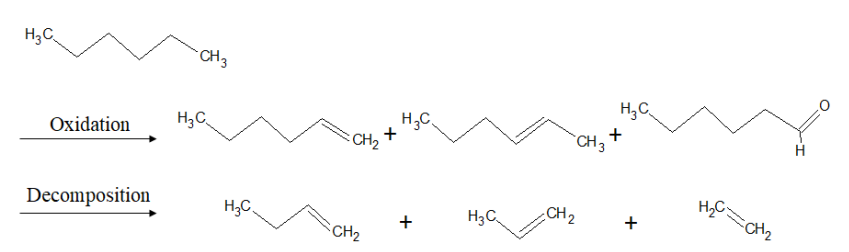

Scheme I. Oxidation and reduction of n-hexane

Kaiser et al. [12] showed that; the major primary products formed in the case of iso-pentane fuel, using HCCI engine single cylinder, were; $17 \%$ 2-methyl-1-butene, $10 \%$ 3-methyl-1-butene, 9\% 2-methyl-2-butene, $8 \%$ isobutene, $4 \%$ 2-butene, and 3\% 3-methyl-tetrahydrofuran, in addition to high yield formaldehyde (29\%). In the case of iso-octane, the major primary products were: $39 \%$ isobutene and $29 \%$ formaldehyde.

The results of hydrocarbon speciation from HCCI engine revealed that the unburned fuel was the main product seen in the exhaust followed by methane [13]. Oxidized and decomposed products were also detected; the highest concentration of olefins resulted from the combustion was ethylene and the highest concentration of aldehydes was formaldehyde. Naphthenes and other aromatics were also detected in the exhaust gases but with very small concentrations.

Dec et al. [14], drew detailed exhaust speciation measurements from an HCCI engine fueled with isooctane over a range of air/fuel ratio. Similar to n-heptane, the unburned isooctane was by far the largest contributor to the emissions at all fueling rates, followed by formation of 2-methyl-1propene (isobutene), which is a known breakdown product of isooctane. Different HC species were detected and identified as breakdown products of isooctane (e.g. methane, ethylene, and propylene).

Shibata et al. [15] examined the effects of the fuel components structure on auto-ignition characteristics and HCCI engine performance. Thirteen different hydrocarbons, four different paraffins, three different naphthenes, and six different aromatics, were chosen for this investigation. The results showed the relation between the hydrocarbon structure and research octane number. It was clearly shown that the ignitability differences of the hydrocarbon were mainly caused by the straight chain length of alkanes and side chains, the ring size of naphthenes, and the Benzene ring in aromatics.

Hunicz and Medina [16] provide comprehensive quantitative data on hydrocarbon species concentrations in exhaust gases from a (SI/HCCI) engine fuelled with gasoline. A Fourier transform infrared gas analyser was used for detailed speciation of hydrocarbons upstream and downstream of TWC. A fractions of selected species in HCs emissions for variable operating conditions was detected $\left(\mathrm{CH}_{4}, \mathrm{C}_{2} \mathrm{H}_{2}, \mathrm{C}_{2} \mathrm{H}_{4}, \mathrm{C}_{2} \mathrm{H}_{6}, \mathrm{C}_{3} \mathrm{H}_{6}, \mathrm{C}_{4} \mathrm{H}_{6}, \mathrm{n}-\mathrm{C}_{5} \mathrm{H}_{12}\right.$, iso $\mathrm{C}_{5} \mathrm{H}_{12}$ and $\mathrm{C}_{6} \mathrm{H}_{5} \mathrm{CH}_{3}$ ). However, emission of all species are higher for HCCI combustion mode under late injection strategy than for SI combustion.

Yang et. al. [17] concluded that unburned hydrocarbon emissions in HCCI engine are strongly dependent on the parent fuel's autoignition chemistry, with less dependence on the peak bulk temperature, in contrast to the $\mathrm{CO}$ emissions.

In our previous work Elghawi et al. [18, 19], we reported on the relationship between the commercial gasoline fuel components containing $2 \% \mathrm{w} / \mathrm{w}$ ethanol and the combustion products in the engine exhaust of carbonyl emissions as well as vapour-phase and particulate-bound PAHs profile generated by the same engine and using the same winter grade commercial gasoline.

The objective of this study is to identify and quantify the exhaust hydrocarbon species ranged from $C_{5}$ to $C_{11}$, formed in the combustion of the winter grade commercial gasoline during SI and HCCI combustion mode.

\section{Experimental}

\subsection{The Engine}

The experimental engine was a $3 \mathrm{~L}$ gasoline directinjection (wall guided) V6 engine; the engine specifications are listed in Table 1. The engine was coupled to a Froude EC 38 eddy current dynamometer. The valve-train was modified to permit operation in HCCI mode by the provision of a cam profile switching mechanism. This cam profile switching (CPS) system was used to switch between SI and HCCI modes. This system allowed on-line switching of valve lift from $9 \mathrm{~mm}$ (SI operation) to $3 \mathrm{~mm}$ (HCCI) operation. The HCCI operation was achieved by internal EGR, using negative valve overlap that trap exhaust gases in order to retain enough energy for auto-ignition. The penalty of HCCI operation by the trapping of EGR is typically the limitation of its operating envelope (Fig. 1). At the low boundary, it is limited by misfire due to limited tolerance for EGR. Whereas, at the high boundary the limitation is typically due to knock tendencies. The variable valve timing system of the engine made it possible to change the valve timing for the inlet and exhaust valves within a 60 crank angle (CA) degree range. The HCCI starting procedure involves a warm-up period when the engine is operated in SI mode until the oil and coolant temperatures reach $90^{\circ} \mathrm{C}$. In HCCI mode the engine was operated with a wideopen throttle significantly reducing pumping losses. A DSPACE-based system coupled to a computer using MATLAB/SIMULINK software was used to control the engine parameters during operation and data acquisition. The fuel flow rate to the engine was measured with the use of an AVL gravimetric meter. The fuel injection pulse width was adjusted by the engine management system to maintain the required engine operation condition and $\mathrm{A} / \mathrm{F}$ ratio.

Table 1. Engine specification summary

\begin{tabular}{|l|c|}
\hline Description & Specification \\
\hline Engine type & Jaguar research V6, 24-V, GDI \\
\hline Bore & $79.5 \mathrm{~mm}$ \\
\hline Stroke & Gasoline, RON 95 \\
\hline Fuel & 11.3 \\
\hline Compression ratio & Variable \\
\hline Intake valve timing & Variable \\
\hline Exhaust valve timing & Variable \\
\hline Intake temperature & \\
\hline
\end{tabular}




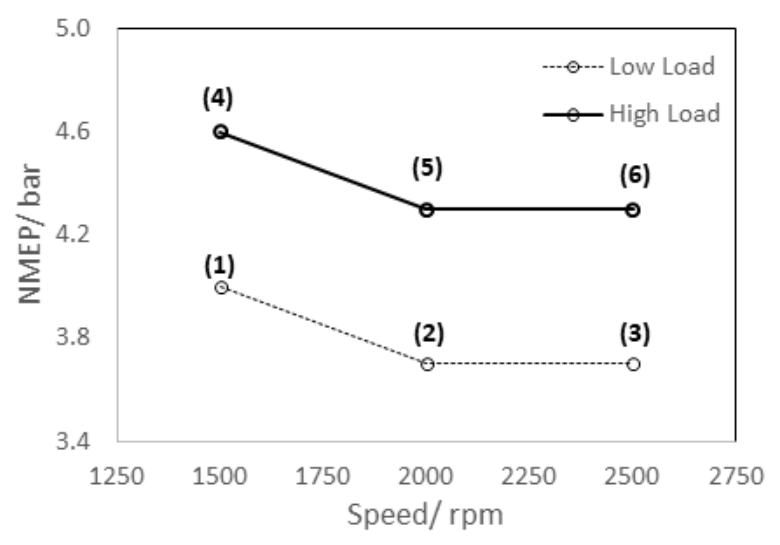

Fig. 1. Selected points on speed/load map from this study

\subsection{Gasoline Fuel used}

The fuel used in this study was standard unleaded gasoline, its research octane number (RON) is 95 . The properties of winter grade commercial gasoline containing $2 \%$ w/w ethanol $\left(\mathrm{C}_{2} \mathrm{H}_{5} \mathrm{OH}\right)$ are listed in Table 2.

Table 2. Properties and composition of gasoline used as received from the distributed company

\begin{tabular}{|l|c|c|}
\hline Winter grade gasoline & $\% \mathrm{w} / \mathrm{w}$ & RON \\
\hline Oxygen & 0.74 & \\
\hline Alkanes & 57 & \\
\hline Aromatic (total) & 36 & \\
\hline Toluene & 12 & 120 \\
\hline p- and o-Xylene & 11 & 145,120 \\
\hline Trimethylbenzene & 10 & $>100$ \\
\hline Other aromatics & 3 & \\
\hline Alkenes & 5.7 & \\
\hline Additives & $<1.0$ & \\
\hline
\end{tabular}

The composition and concentration of winter grade commercial gasoline used in this study were analyzed by GC-MS, Hewlett-Packard HP 5890 series II connected to MS, TRIO-1. The gas-chromatographic parameters used for speciation of the commercial gasoline used in this study presented in Table 3, and the result of the analysis is shown in Fig. 2.

Table 3. Gas-chromatographic parameters used for speciation of commercial gasoline

\begin{tabular}{|c|c|}
\hline Parameters & HP 5890 series II \\
\hline Column: & J\&W Scientific DB-1: $50 \mathrm{~m} ; 0.32 \mathrm{~mm} \mathrm{ID;} 0.25 \mu \mathrm{m}$ film \\
\hline Detector: & $\begin{array}{l}\text { MS, TRIO-1 } \\
\text { Ion Source } 200{ }^{\circ} \mathrm{C} ; 40: 450 \mathrm{amu}\end{array}$ \\
\hline $\begin{array}{l}\text { Oven } \\
\text { ramp: }\end{array}$ & $\begin{array}{l}-80{ }^{0} \mathrm{C} \text { initial; } 3 \text { minutes hold } \\
\cdot 4{ }^{0} \mathrm{C} \text { /minute to } 250{ }^{0} \mathrm{C} \\
\text { - } 5 \text {-minute final hold (Flush) } \\
\text { - Total run is } 50 \text { minutes }\end{array}$ \\
\hline Flow Rate: & $6 \mathrm{ml} / \mathrm{minute} ; \mathrm{He}$ \\
\hline
\end{tabular}

Identifying the hydrocarbon components in the fuel is the key step in speciation HCs in the engine exhaust. By using retention time of some known compounds and the NIST library together, the peaks in the chromatogram of the analyte were identified and assigned to their proper compound. The fuel used consists primarily light aliphatic hydrocarbons (butane, pentane, methyl-pentane, hexane, methyl-hexane, heptane and octane), aromatic compounds (toluene, p\&o-xylenes and trimethyl-benzenes), and small amount of olefinic hydrocarbons (pentenes, hexenes, heptenes, octenes and nonenes).

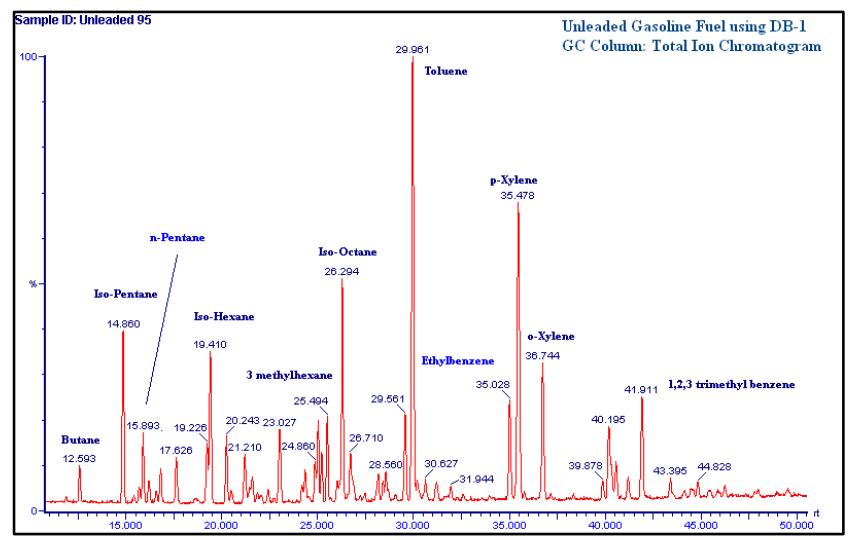

Fig. 2. GC-MS characterisation of the components in used commercial gasoline fuel

\subsection{Analysis of Regulated Gases}

A Horiba MEXA 7100 DEGR equipped with a heated intake line was used to measure regulated emissions, including total hydrocarbon, carbon monoxide, carbon dioxide, $\mathrm{NO}_{\mathrm{x}}$ and oxygen in the exhaust. The heated line and pre-filter are maintained at $190^{\circ} \mathrm{C}$. The analyzer equipped with flame ionization detector (FID) was used to measure total hydrocarbon in ppm methane $\left(\mathrm{CH}_{4}\right)$ equivalent. The measurement of $\mathrm{HC}$ represents wet $\mathrm{HC}$ concentration. Carbon monoxide $(\mathrm{CO})$ and carbon dioxide $\left(\mathrm{CO}_{2}\right)$ were analyzed by non-dispersive infrared (NDIR) detector and $\mathrm{NO}_{x}$ by a chemiluminescence detector (CID). The $\lambda$ (air/fuel ratio relative to stoichiometric), temperature and pressure of the exhaust gases at the engine exhaust manifold were also measured. The system was calibrated using suitable bottled span and zero calibration gases by using British Oxygen Company (BOS) standards with different concentrations.

The calculations of specific emissions are based on the Directive 1999/96/EC of the European Parliament and of the Council of the European Union [20]. This document describes the procedures and rules which should be applied when gaseous emissions from internal combustion engines are considered.

\subsection{Speciation of Hydrocarbon $\mathrm{C}_{5}-\mathrm{C}_{11}$}

Hydrocarbon speciation was performed online by a GCMS, Fisons GC 8000 series connected to MS, Fisons MD 800 . The gas samples were introduced via the heated line at $200^{\circ} \mathrm{C}$ into a six port Valco valve outfitted with a $1 \mathrm{ml} \mathrm{sam}$ ple loop. A 30 -meter long x $0.53 \mathrm{~mm}$ i.d. capillary column with a $3 \mu \mathrm{m}$ film thickness DB-1 was used, which allowed the polar and non-polar compounds to be detected simultaneously. The column head pressure was maintained at 35 psi. The helium carrier gas flow rate was pressure controlled with a flow rate of $6 \mathrm{ml} / \mathrm{min}$. The component standards were generally stable in concentration when the gas was released from the cylinder at this flow rate. The temperature program settings (Table 4) permits to flush out the heavier hydrocarbon to cope with different engine operational mode. Standard mixtures of paraffin's, olefins and HCs with known concentrations were used as a reference sample. The retention time of each species were calibrated 
daily before each set of experiment by analyzing a standard sample of gases that contain 15 components purchased from British Oxygen Company (BOS). The concentration of the components of standard sample were generally stable when the gas was released from the cylinder at $6 \mathrm{ml} / \mathrm{min}$ flow rate. The runtime was 22 minutes and the retention time of detected species is given in Table 5. The chromatograms obtained for the emission products from both operation modes of the engine at the same speed and load points at NMEP 4.0 bar and $2000 \mathrm{rpm}$ engine speed and running at lambda $=1$ are shown in Fig. 3, and the hydrocarbon species $\left(\mathrm{C}_{5}-\mathrm{C}_{11}\right)$ are presented in Table 4 .

Table 4. Gas-chromatographic parameters used for detection of $\mathrm{C}_{5}-\mathrm{C}_{11}$ compounds

\begin{tabular}{|l|l|}
\hline Parameters & GC 8000 series \\
\hline Column & DB-1, 30 m; 0.53 mm ID; $3 \mu \mathrm{m}$ film \\
\hline Detector: & MS, Fisons MD 800 \\
& Ion Source $200^{\circ} \mathrm{C} ; 35: 200 \mathrm{amu}$ \\
\hline Oven ramp & $\bullet 40^{\circ} \mathrm{C}$ initial; 2 minutes hold \\
& $\bullet 10^{\circ} \mathrm{C} /$ minute to $200^{\circ} \mathrm{C} ; 5$ minutes hold \\
& $\cdot 5$-minute final hold (Flush) \\
\hline Flow Rate & $6 \mathrm{ml} /$ minute; $\mathrm{He}$ \\
\hline
\end{tabular}

Table 5. Retention time of standard sample components

\begin{tabular}{|c|c|c|}
\hline Peak No & Compound & Retention Time (minute) \\
\hline 1 & Iso-Butane & 3.231 \\
2,3 & 1,3-Butadiene + n-Butane & 3.401 \\
4 & Iso-pentane & 4.161 \\
\hline 5 & 1-Pentene & 4.321 \\
6 & n-Pentane & 4.471 \\
7 & n-Hexane & 6.012 \\
8 & Benzene & 7.233 \\
\hline 9 & n-Heptane & 8.173 \\
10 & Iso-octane & 8.785 \\
\hline 11 & Toluene & 9.534 \\
\hline 12 & EthylBenzene & 11.54 \\
\hline 13 & p-xylene & 11.72 \\
\hline 14 & Naphthalene & 18.19 \\
\hline 15 & Methyl-naphthalene & 20.66 \\
\hline
\end{tabular}

\begin{tabular}{|c|c|c|c|c|c|c|c|c|c|c|c|c|c|c|}
\hline \multicolumn{3}{|c|}{ Common conditions } & \multicolumn{6}{|c|}{ SI mode } & \multicolumn{6}{|c|}{ HCCI mode } \\
\hline Point & $\begin{array}{c}\text { Speed } \\
\text { rpm }\end{array}$ & $\begin{array}{c}\text { NMEP } \\
\text { bar }\end{array}$ & $\begin{array}{c}\text { Total HC } \\
\text { ppm eq. } \\
\text { to } \mathrm{CH}_{4}\end{array}$ & $\begin{array}{c}\mathrm{CO} \\
\%\end{array}$ & $\begin{array}{c}\mathrm{CO}_{2} \\
\%\end{array}$ & $\begin{array}{l}\mathrm{NO}_{\mathrm{x}} \\
\mathrm{ppm}\end{array}$ & $\begin{array}{l}\mathrm{O}_{2} \\
\%\end{array}$ & $\begin{array}{c}\text { Exh. } \\
\text { Temp } \\
{ }^{0} \mathrm{C}\end{array}$ & $\begin{array}{c}\text { Total HC } \\
\text { ppm eq. } \\
\text { to } \mathrm{CH}_{4}\end{array}$ & $\begin{array}{c}\mathrm{CO} \\
\%\end{array}$ & $\begin{array}{c}\mathrm{CO}_{2} \\
\%\end{array}$ & $\begin{array}{l}\mathrm{NO}_{\mathrm{x}} \\
\mathrm{ppm}\end{array}$ & $\begin{array}{l}\mathrm{O}_{2} \\
\%\end{array}$ & $\begin{array}{c}\text { Exh. } \\
\text { Temp } \\
{ }^{\circ} \mathrm{C}\end{array}$ \\
\hline (1) & 1500 & 4.0 & 1920 & 0.63 & 13.84 & 420 & 1.06 & 572 & 3400 & 0.52 & 14.01 & 42 & 1.19 & 382 \\
\hline (2) & 2000 & 3.7 & 1760 & 0.88 & 13.74 & 830 & 1.05 & 601 & 3040 & 0.55 & 13.92 & 75 & 1.19 & 384 \\
\hline (3) & 2500 & 3.7 & 1730 & 0.75 & 13.80 & 1080 & 1.02 & 641 & 2830 & 0.68 & 13.92 & 114 & 1.10 & 398 \\
\hline (4) & 1500 & 4.6 & 2260 & 0.69 & 13.84 & 630 & 1.09 & 591 & 2660 & 0.62 & 14.17 & 166 & 0.95 & 402 \\
\hline (5) & 2000 & 4.3 & 1960 & 0.76 & 13.81 & 1040 & 1.07 & 624 & 2190 & 0.63 & 14.21 & 104 & 0.80 & 404 \\
\hline (6) & 2500 & 4.3 & 1430 & 0.70 & 14.36 & 1140 & 0.86 & 662 & 1640 & 0.47 & 14.39 & 163 & 0.74 & 432 \\
\hline
\end{tabular}

Table 7. Operation conditions and parameters of the V6 engine in SI and HCCI modes (all for $\lambda=1.0$ ). Normalized emission values and fuel consumption

\begin{tabular}{|c|c|c|c|c|c|c|c|c|c|c|}
\hline \multicolumn{3}{|c|}{ Common conditions } & \multicolumn{4}{|c|}{ SI mode } & \multicolumn{4}{|c|}{ HCCI mode } \\
\hline Point & $\begin{array}{c}\text { Speed } \\
\text { rpm }\end{array}$ & $\begin{array}{l}\text { NMEP } \\
\text { bar }\end{array}$ & $\begin{array}{c}\mathrm{HC} \\
\mathrm{g} / \mathrm{kWh}\end{array}$ & $\begin{array}{c}\mathrm{CO} \\
\mathrm{g} / \mathrm{kWh}\end{array}$ & $\begin{array}{l}\mathrm{NO}_{\mathrm{x}} \\
\mathrm{g} / \mathrm{kWh}\end{array}$ & $\begin{array}{l}\text { Fuel Consumption } \\
\mathrm{g} / \mathrm{h}\end{array}$ & $\begin{array}{c}\mathrm{HC} \\
\mathrm{g} / \mathrm{kWh}\end{array}$ & $\begin{array}{c}\mathrm{CO} \\
\mathrm{g} / \mathrm{kWh}\end{array}$ & $\begin{array}{l}\mathrm{NO}_{\mathrm{x}} \\
\mathrm{g} / \mathrm{kWh}\end{array}$ & $\begin{array}{l}\text { Fuel Consumption } \\
\mathrm{g} / \mathrm{h}\end{array}$ \\
\hline (1) & 1500 & 4.0 & 7.30 & 34.8 & 4.2 & 3500 & 12.70 & 23.6 & 0.20 & 3000 \\
\hline (2) & 2000 & 3.7 & 7.00 & 41.4 & 7.8 & 3900 & 10.10 & 25.4 & 0.09 & 3300 \\
\hline (3) & 2500 & 3.7 & 6.10 & 36.6 & 9.8 & 4400 & 9.10 & 27.2 & 0.10 & 3700 \\
\hline (4) & 1500 & 4.6 & 7.50 & 35.2 & 7.6 & 4400 & 8.90 & 26.7 & 1.40 & 3800 \\
\hline (5) & 2000 & 4.3 & 7.30 & 36.4 & 10.0 & 5100 & 7.40 & 27.0 & 0.80 & 4600 \\
\hline (6) & 2500 & 4.3 & 5.40 & 35.4 & 11.1 & 5500 & 6.00 & 21.2 & 1.30 & 4900 \\
\hline
\end{tabular}


Hydrocarbon species in SI and HCCI engine using winter grade commercial gasoline

Table 8. Measured species in the exhaust at different conditions in SI and HCCI modes [ppm]

\begin{tabular}{|c|c|c|c|c|c|c|}
\hline \multicolumn{7}{|c|}{ SI mode } \\
\hline Testing point & Point (1) & Point (2) & Point (3) & Point (4) & Point (5) & Point (6) \\
\hline Speed/rpm & 1500 & 2000 & 2500 & 1500 & 2000 & 2500 \\
\hline NMEP/bar & 4.0 & 3.7 & 3.7 & 4.6 & 4.3 & 4.3 \\
\hline Benzene & 128 & 141 & 151 & 148 & 155 & 165 \\
\hline Toluene & 382 & 331 & 319 & 400 & 358 & 262 \\
\hline $\mathrm{C}_{6} \mathrm{H}_{6} \%$ in $\mathrm{C}_{1}-\mathrm{C}_{11}$ & $6.7 \%$ & $8.0 \%$ & $8.7 \%$ & $6.5 \%$ & $7.6 \%$ & $11.5 \%$ \\
\hline $\mathrm{C}_{7} \mathrm{H}_{8} \%$ in $\mathrm{C}_{1}-\mathrm{C}_{11}$ & $19.9 \%$ & $18.8 \%$ & $18.4 \%$ & $17.7 \%$ & $18.2 \%$ & $18.3 \%$ \\
\hline Total HC $\left(\mathrm{C}_{1}-\mathrm{C}_{11}\right)$ & 1920 & 1760 & 1730 & 2260 & 1960 & 1430 \\
\hline \multicolumn{7}{|c|}{ HCCI mode } \\
\hline Benzene & 38 & 76 & 81 & 79 & 91 & 113 \\
\hline Toluene & 608 & 512 & 447 & 434 & 334 & 219 \\
\hline $\mathrm{C}_{6} \mathrm{H}_{6} \%$ in $\mathrm{C}_{1}-\mathrm{C}_{11}$ & $1.1 \%$ & $2.5 \%$ & $2.8 \%$ & $2.9 \%$ & $4.1 \%$ & $6.9 \%$ \\
\hline $\mathrm{C}_{7} \mathrm{H}_{8} \%$ in $\mathrm{C}_{1}-\mathrm{C}_{11}$ & $17.8 \%$ & $16.8 \%$ & $15.8 \%$ & $16.3 \%$ & $15.3 \%$ & $13.4 \%$ \\
\hline Total HC $\left(\mathrm{C}_{1}-\mathrm{C}_{11}\right)$ & 3400 & 3040 & 2830 & 2660 & 2190 & 1640 \\
\hline
\end{tabular}

\section{Results and discussion}

\subsection{Speciation and Quantification of Heavier \\ Hydrocarbon $\left(\mathbf{C}_{5}-\mathbf{C}_{11}\right)$}

The benzene mole fractions increased by increasing the operation load (Table 8). Benzene results from the incomplete combustion of toluene and other alkyl-benzenes, as observed by Kaiser et al. [21]. The formation of benzene during combustion of the fuel used in this study that contains $<1.0 \%$ benzene explains its observed enrichment in the exhaust relative to other aromatic fuel components available in this commercial gasoline fuel. Emission of benzene increase by increasing the engine speed and load and constitutes an appreciable fraction of the total emission (Table 8). In our work; the observed benzene concentration; is ranging from $38 \mathrm{ppm}$ in case of HCCI mode point (1) to $165 \mathrm{ppm}$ in case of the engine operation on SI mode point (6). This difference in the concentration is due to the increased post-flame oxidation in SI mode, which explains why in SI mode benzene formation is favoured over toluene. This behavior was also observed by Villinger et al. [22].

Table 9. Hydrocarbon species $\left(\mathrm{C}_{5}-\mathrm{C}_{11}\right)$ at NMEP 4.0 [bar] and $2000 \mathrm{rpm}$ engine speed, of the V6 Engine in SI and HCCI modes and for $\lambda=1.0$

\begin{tabular}{|l|c|c|}
\hline Hydrocarbon species & HCCI mode [ppm] & SI mode [ppm] \\
\hline Iso-pentane $\mathrm{C}_{5} \mathrm{H}_{11}$ & 102 & 38 \\
\hline Benzene $\mathrm{C}_{6} \mathrm{H}_{6}$ & 82 & 148 \\
\hline 1-pentene $\mathrm{C}_{5} \mathrm{H}_{10}$ & 23 & 27 \\
\hline n-pentane $\mathrm{C}_{5} \mathrm{H}_{12}$ & 61 & 46 \\
\hline n-hexane $\mathrm{C}_{6} \mathrm{H}_{14}$ & 57 & 33 \\
\hline Iso-octane $\mathrm{C}_{8} \mathrm{H}_{18}$ & 18 & 83 \\
\hline Toluene $\mathrm{C}_{7} \mathrm{H}_{8}$ & 423 & 344 \\
\hline Ethylbenzene $\mathrm{C}_{8} \mathrm{H}_{10}$ & 89 & 123 \\
\hline p-xylene $\mathrm{C}_{8} \mathrm{H}_{10}$ & 421 & 305 \\
\hline Naphthalene $\mathrm{C}_{10} \mathrm{H}_{8}$ & 309 & 251 \\
\hline Methyl naphthalene $\mathrm{C}_{11} \mathrm{H}_{10}$ & 211 & 97 \\
\hline Total $\mathrm{C}_{5}-\mathrm{C}_{11}$ & 1796 & 1495 \\
\hline Total $\mathrm{C}_{1}-\mathrm{C}_{11}$ & 2615 & 1860 \\
\hline Percentage of $\mathrm{C}_{5}-\mathrm{C}_{11} / \mathrm{C}_{1}-\mathrm{C}_{11}$ & $68.7 \%$ & $80.3 \%$ \\
\hline
\end{tabular}

The engine operation at HCCI mode follows the same trend as in the SI mode (Table 6 and 8), but since the combustion temperature is always lower for HCCI (Table 6), the oxidation of fuel paraffin is less. As a result, the amount of total olefins, methane and benzene are lower than in SI mode, for instance the total HC at point (1) in HCCI mode was $3400 \mathrm{ppm}$ and in SI mode was $1920 \mathrm{ppm}$ (Table 8).
Tailpipe studies observed that the exhaust benzene emissions are dependent on the benzene and the total aromatics content of the fuel [23, 24]. Although benzene currently is not regulated, it has raised health concern especially if generated in appreciable quantities [25, 26].

For toluene as well as for the other aromatics (e.g. xylenes) except benzene, there is a decrease in the exhaust concentration when both engine speed and load conditions are increased, a trend seen in both combustion modes. In the SI mode the concentration of toluene is always lower under the same operation conditions. Both toluene and xylene, are contributing in the formation of benzene due to their aromatic based structure. Schuetzle et al. [27] showed that a substantial increase in benzene concentration was observed when toluene or xylene is added to the gasoline fuel.

\subsection{Formation of Hydrocarbon and regulated emissions in SI and HCCI modes}

In gasoline engines (SI/HCCI) under stoichiometric conditions, the balance of the $\mathrm{HC}$ emissions from paraffinic or alkanes, (more than half of the composition of the fuel in this study) consists primarily of olefins formed by $\beta$-scission of $\mathrm{C}-\mathrm{C}$ bonds of the higher molecular weight fuels; followed by $\mathrm{H}$-atom abstraction. It was concluded by Kaiser et al. [21, 28, 29] that for alkanes, $\beta$-scission and $\mathrm{H}$-atom loss reactions play important roles in determining the combustion products emitted from the exhaust once an alkyl radical is formed. To a lesser extent, disproportionation reactions forming methyl radicals may generate $\mathrm{C}_{2} \mathrm{H}_{4}$ from highly branched alkanes such as iso-octane [21]. Due to the different molecular structures of parent paraffines, the $\mathrm{H}$-abstraction results in a variety of alkyl radicals. The alkyl radicals are consumed in three parallel paths: (i) abstraction of another H-atom from an alkyl radical by another alkyl radical to form an olefin, (ii) abstraction of another $\mathrm{H}$-atom from an alkyl radical by oxygen to form an olefin and a hydroperoxy radical, and (iii) oxygen addition to the radical to form an alkyl peroxy radical (scheme II).

$$
\begin{gathered}
\mathrm{R}-\mathrm{CH}_{2}-\mathrm{CH}_{2}-\mathrm{CH}_{2}-\mathrm{R}^{\prime} \longrightarrow \mathrm{R}-\mathrm{CH}_{2}{ }^{\circ}+\mathrm{CH}_{2}{ }^{\circ} \\
-\mathrm{CH}_{2}-\mathrm{R}^{\prime}(\beta-\text { scission }) \\
\mathrm{R}-\mathrm{CH}_{2}^{\circ}+\mathrm{CH}_{2}{ }^{\circ}-\mathrm{CH}_{2}-\mathrm{R}^{\prime} \longrightarrow \mathrm{R}-\mathrm{CH}_{3}+\mathrm{CH}_{2} \\
\quad=\mathrm{CH}-\mathrm{R} \\
\mathrm{O}_{2}+\mathrm{CH}_{2}^{\circ}-\mathrm{CH}_{2}-\mathrm{R}^{\prime} \longrightarrow \mathrm{H}-\mathrm{O}_{2}{ }^{\circ}+\mathrm{CH}_{2} \\
=\mathrm{CH}-\mathrm{R}
\end{gathered}
$$




$$
\begin{gathered}
\mathrm{O}_{2}+\mathrm{CH}_{2}{ }^{\circ}-\mathrm{CH}_{2}-\mathrm{R}^{\prime} \longrightarrow \mathrm{O}_{2}^{\circ}-\mathrm{CH}_{2} \\
\quad=\mathrm{CH}-\mathrm{R}
\end{gathered}
$$

Scheme II. $\beta$-scission and hydrogen abstraction reaction of alkane

At high temperatures, paraffinic species are converted into olefins through $\mathrm{H}$-atom abstraction reaction, as in the case of SI operation mode, in which there is a build-up of methyl radicals that recombine into ethane. However, in HCCI operation mode, no such reaction occurs, and therefore ethane was not detected in HCCI emissions [30].

Abstraction of $\mathrm{H}$-atoms also occurs from alkenes at high temperature of particular importance, the abstraction of allylic $\mathrm{H}$-atoms (H-atoms bonded to a carbon atom next to a double bond). There are three types of $\mathrm{H}$-atom abstraction from alkenes that depend on the type of abstractable $\mathrm{H}$-atoms (Scheme III), these types are: (1) Abstraction of primary allylic $\mathrm{H}$-atom if it is bonded to a carbon atom that bonded to two other $\mathrm{H}$ atoms. (2) Abstraction of secondary allylic $\mathrm{H}$-atom if it is bonded to a carbon atom bonded to one other $\mathrm{H}$ atom; and (3) Abstraction of tertiary allylic $\mathrm{H}$-atom if it is bonded to a carbon atom bonded to no other $\mathrm{H}$ atom. Abstraction of an allylic $\mathrm{H}$-atom leads to the formation of a resonance-stabilized radical as it is shown in scheme III.<smiles>C=C</smiles>

$\left(1^{0}\right)$
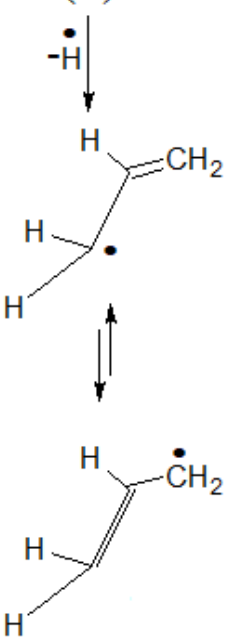

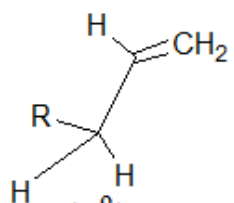

$\left(2^{\circ}\right)$
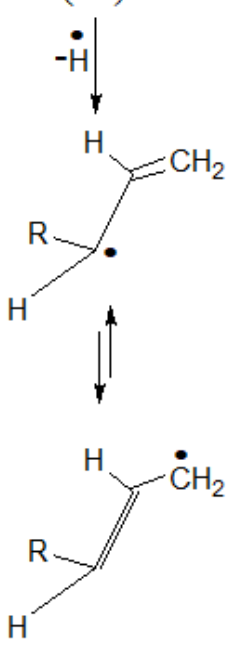

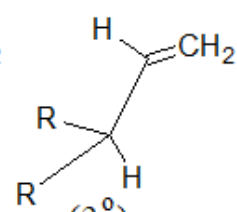

$\left(3^{\circ}\right)$
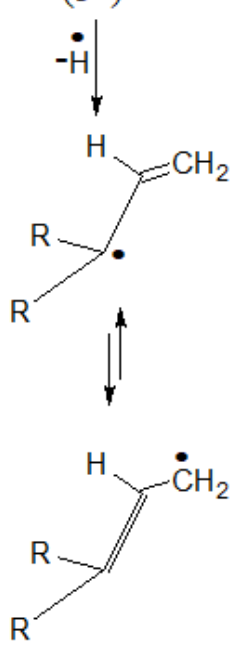

Scheme III. Abstraction of an allylic H-atom

Aromatics constitute approximately one third of the composition of the commercial gasoline used in this study. These aromatics contribute to the high-octane rating and high energy density. Due to the high stability of the aromatic rings, the $\mathrm{H}$-atom abstraction is difficult and slow. As a result, the induction period for aromatics oxidation is longer than for saturated HCs [31]. An engine experiment by Kaiser et al. [28] involving a mixture of ethylbenzene and the three xylene isomers (ortho-, meta- and para-), however, gave mainly aromatic emissions, which were predominantly benzene, toluene and styrene. Gregory and Jackson [32], investigated the mechanisms for the formation of exhaust hydrocarbon in SI engine, fueled with deuterium-labelled the three xylene isomers. The aromatic HCs produced by burning each of the three xylene isomers were benzene, toluene, ethylbenzene, styrene and ethyl toluene. The aliphatic observed included 1,3-butadiene, ethane and ethylene [30]. The common low molecular weight $\mathrm{HC}$ compounds emitted in both modes are methane, ethylene, propylene, n-butane, 1-pentene and iso-pentane, while the heavier molecular weight $\mathrm{HC}$ compounds are benzene and toluene are emitted. Iso-octane, ethyl-benzene and xylenes were detected but not measured.

However, at a lower temperature, the reaction between methyl and oxygen favours the formation of methyl peroxide and aldehydes. Generally, alkanes react with oxygen to form peroxy radicals. These radicals are stable at low temperature, and unstable at high temperature. So, in the case of HCCI mode, because the temperature is lower compared to SI mode, the radicals formed survive longer, and thus the chance for the radicals to rearrange and form an aldehyde and hydroxyl radicals are higher. To make a fuller comparison between SI mode and HCCI mode, and to check the level of formaldehyde formed in the HCCI mode; it would be useful to conduct investigation using Liquefied Petroleum Gas (LPG) fuel, in which there are only two alkane components and no aromatics that complicate the picture (this is quite feasible as LPG is readily available).

The raw emissions of $\mathrm{NO}_{\mathrm{x}}$ and $\mathrm{HC}$ are shown in Table 6 , the opposite behaviour is exhibited with respect to the residual gas content comparing SI to HCCI modes. The emission of $\mathrm{NO}_{\mathrm{x}}$ is significantly reduced for lower loads when there is increased residual gas fraction and thus a diluted mixture, reaching extremely low concentrations. $\mathrm{HC}$ emissions, on the contrary, rise significantly in this region, which is very probably due to incomplete combustion. Data obtained on the contribution of $\mathrm{C}_{5}-\mathrm{C}_{11}$ (an indicator of the amount of unburned fuel) to the total exhaust hydrocarbon with variation in engine speed and load values for both SI and HCCI modes. The $\mathrm{C}_{5}-\mathrm{C}_{11}$ ratio is frequently used to describe the extent to which fuels burn in an engine. In this investigation, it was found that in HCCI mode the proportion of species attributed to $\mathrm{C}_{5}-\mathrm{C}_{11}$ in total $\mathrm{HC}$ is higher than in the SI mode.

The low combustion temperatures achieved at HCCI mode operating points, almost completely avoids $\mathrm{NO}_{\mathrm{x}}$ formation compare to SI mode reduction but leading to combustion attenuation due to heat transfer in the near-wall region. While $\mathrm{NO}_{\mathrm{x}}$ results measured in this study fall rather dramatically as expected, somewhat surprisingly, however, raw emissions of CO in HCCI mode are seen to be slightly lower for all operating points when compared to SI mode. The reduction in $\mathrm{CO}$ emission is likely caused by the recycling of burned gases and subsequent conversion into $\mathrm{CO}_{2}$ in the next cycle [33]. One other result concerns the potential for exhaust gas to be used in fuel reforming to produce hydrogen that would be helpful in the extension of the lower load range for HCCI operation. The exhaust gas temperature remains between 382 and $432^{\circ} \mathrm{C}$ throughout the HCCI operating region. This relatively high exhaust temperature 
is partly due to high load and to a relatively low compression ratio. A quite substantial residual gas fraction of hot gases is required and supplied by the NVO operation. Although not in all cases of HCCI operation exhaust temperatures be expected to be so high, in the cases presented here this temperature level is fully sufficient for exhaust gas after-treatment using a three-way catalyst or oxidation catalyst. This may be insufficient for a straightforward fuel reforming process and may have to be boosted by some initial partial oxidation in the reformer as in fuel reforming for diesel engines.

As a result of this study and our previous work by Elghawi et al. [18, 19], a full spectrum of hydrocarbon $\left(\mathrm{C}_{5}\right.$ to $\mathrm{C}_{11}$ ), Carbonyls, vapour-phase and particulate-bound PAHs profile generated in the combustion of gasoline during SI and HCCI combustion mode can be obtained.

\section{Conclusions}

The hydrocarbon emission is heavily dependent on fuel composition, engine operation and combustion mode (i.e. HCCI or SI). Engine-out emissions analysis showed that the hydrocarbon content of HCCI exhaust (Low Temperature Combustion Engine) contained more of the heavier species (e.g. toluene, p-xylene, Naphthalene and Methyl naphthalene) than that observed in conventional SI operation mode. Overall, HCCI operation resulted in improve fuel consumption and highly reduction in $\mathrm{NO}_{\mathrm{x}}$ compared to conventional combustion (Spark-Ignited operation). The results also show that the monocyclic aromatic hydrocarbon such as toluene are present at higher concentrations in the exhaust under HCCI operation than in the SI case. On the other hand, benzene concentrations are higher in the SI exhaust.

\section{Acknowledgements}

One of the authors (Elghawi) would like to acknowledge the Libyan Government for the provision of the scholarships and Professor Wyszynski and his group for accepting him in their laboratory in the department of Mechanical Engineering at the University of Birmingham, the UK. Jaguar is acknowledged for supporting the work with the research engine.

\section{Bibliography}

[1] JOHNSON, E.S., LANGARD, S., LIN, Y. A critique of Benzene exposure in general population. Science of the Total Environment. 2007, 374,183.

[2] US Environmental Protection Agency. Estimating cancer risk from outdoor concentrations of hazardous air pollutants in 1990. EPA, Environmental Research Section. 2000, 82, 194-206.

[3] KOSTRZEWSKI, P., PIOLROWSKI, J. Toluene determination in capillary blood as a biological indicator of exposure to low level of toluene. Polish Journal of Occupational Medicine. Medicine Environmental Health. 1991, 4, 249259.

[4] HAZRATI, S., ROSTAMI, R., FAZLZADEH, M. et al. Benzene, toluene, ethylbenzene and xylene concentrations in atmospheric ambient air of gasoline and CNG refueling stations. Air Quality, Atmosphere \& Health. 2016, 9, 403-409.

[5] ANDERSEN, I., LUNDQVIST, G.R, MOLHAVE, L. et al. Human response to controlled levels of toluene in six-hour exposures. Scandinavian Journal of Work, Environment \& Health. 1983, 9, 405-418.

[6] MAHAVAR et al. Toluene Poisoning Presenting as Bilateral Basal Ganglia Haemorrhage. Journal of The Association of Physicians of India. 2018, 66, 2018.

[7] ATSDR, Agency for Toxic Substances and Disease Registry. Toxicological Profile for Toluene (Update). U.S. Public Health Service, U.S. Department of Health and Human Services.2000, 357 P, Atlanta.

[8] WALLINGTON, T.J., KAISER, W.E., FARRELL V. Automotive fuels and internal combustion engines: a chemical perspective. Chemical Society Reviews. 2006, 35, 335.

[9] EPPING, K., ACEVES, S., BECHTOLD, R. et al. The potential of HCCI combustion for high efficiency and low emissions, SAE Technical Paper. 2002-01-1923, 2002.

[10] WALKER, J., O'HARA, C. Analysis of automobile exhaust gases by mass spectrometry. Analytical Chemistry. 1955, 27(5), 825-828.

[11] TSURUSHIMA, T., SHIMAZAKI, N., ASAUMI, Y. Gas sampling analysis of combustion processes in an HCCI Engine. International Journal of Engine Research. 2000, 1(4), 337.

[12] KAISER, E.W., MARICQ, M.M., XU, N. et al. Detailed HC species and particulate emissions from an HCCI engine as a function of air-fuel ratio. SAE Technical Paper. 2005-013749,2005

[13] LI, H., NEIL, S., CHIPPIOR, W. An Experimental investigation on the emission characteristics of HCCI engine operation using n-heptane. SAE Technical Paper. 2007-01$1854,2007$.

[14] DEC, J.E., DAVISSON, M.L., LEIF, R.N. et al. Detailed HCCI exhaust speciation and the sources of $\mathrm{HC}$ and $\mathrm{OHC}$ emissions, SAE Technical Paper. 2008-01-0053, 2008.

[15] SHIBATA, G., KAWAGUCHI, R., YOSHIDA, S. et al. Molecular structure of hydrocarbon and auto-ignition characteristics of HCCI engines. SAE International Journal of Fuels and Lubricants. 2014, 7, 3.

[16] HUNICZ, J., MEDINA, A. Experimental study on detailed emissions speciation of an HCCI engine equipped with a three-way catalytic converter. Energy. 2016, 117, 388-397.

[17] YANG, R., HARIHARAN, D., ZILG, S. et al. Efficiency and emissions characteristics of an HCCI engine fuelled by primary reference fuels. SAE Technical Paper. 2018-011255, 2018. https://doi.org/10.4271/2018-01-1255.

[18] ELGHAWI, U.M., MAYOUF, A., TSOLAKIS, A. et al. Vapour-phase and particulate-bound PAHs profile generated by an (SI/HCCI) engine from a winter grade commercial gasoline fuel. Fuel. 2010, 89, 2019.

[19] ELGHAWI, U.M., MAYOUF, A. Carbonyl emissions generated by an (SI/HCCI) engine from a winter grade commercial gasoline fuel. Fuel. 2014, 116, 109.

[20] OJEC Official Journal of the European Communities, L44, (16-02-2000).

[21] KAISER, E.W., SIEGL, W.O., HENIG, Y.I. et al. Effect of fuel structure on emission from a spark-ignited engine. Environmental Science \& Technology. 1991, 25(12), 20052012.

[22] VILLINGER, J., FEDERER, W., PRAUN, S. Comparative study of butadiene and B, T, X tailpipe emissions for gasoline of different octane levels. SAE Technical Paper. 200101-1643, 2001.

[23] HECK, R.M., FARRAUTO, R.J. Automobile exhaust catalysts. Applied Catalysis A: General. 2011, 221, 443. 
[24] GANDHI, H.S., GRAHAM, G.W., MCCABE, R.W. Automotive exhaust catalysis. Journal of Catalysis. 2003, 216, 433.

[25] KASPAR, J., FORNASIERO, P., HICKEY, N. Automotive catalytic converters: current status and some perspectives. Catalysis Today. 2003, 77, 419.

[26] GARIN, F. Environmental catalysis. Catalysis Today. 2004, 89, 255.

[27] SCHUETZLE, D., SIEGL, W.O., JENSEN, T.E. et al. The relationship between gasoline composition and vehicle hydrocarbon emissions: A review of current studies and future research needs. Environmental Health Perspectives. 1994, 102 (Suppl 4), 3.

[28] KAISER, E.W., SIEGL, W.O., COTTON, D.F. et al. Effect of fuel structure on emission from a spark-ignited engine. 2. naphthene and aromatic fuels. Environmental Science \& Technology. 1992, 26(8), 1581.

Usama Elghawi - Department of Mechanical

Engineering, Libyan Academy of Graduate Studies.

e-mail: u.elghawi@aee.gov.ly

Ahmed Mayouf - International Study group,

Kingston University, United Kingdom.
[29] KAISER, E.W., SIEGL, W.O., COTTON, D.F. et al. Effect of fuel structure on emission from a spark-ignited engine. 3 . olefinic fuels. Environmental Science \& Technology. 1993, 27(7), 1440.

[30] ELGHAWI, U., MISZTAL, J., TSOLAKIS, A. et al. GCMS speciation and quantification of 1,3-butadiene and other C1-C6 hydrocarbon in SI/HCCI V6 engine exhaust. SAE Technical Paper. 2008-01-0012, 2008.

[31] GLASSMAN, I. Combustion. Academic Press. San Diego 1996.

[32] GREGORY, D., JACKSON, R.A. Mechanisms for the formation of exhaust hydrocarbon in a single cylinder SI engine, fueled with deuterium-labelled ortho-, meta- and paraxylene. Combustion and Flame. 1999, 118, 459.

[33] ZHAO, H. HCCI and CAI engines for the automotive industry. CRC Press. Cambridge 2007.

Athanasios Tsolakis - Department of Mechanical

Engineering, University of Birmingham, United

Kingdom.

e-mail:a.tsolakis@bham.ac.uk 